\title{
El PARTO NATURAL Y LA FAMILIA CRISTIANA
}

\author{
Mrs. Helen Wessel B. A.*
}

Se me ha solicitado presentar a ustedes la tesis de mi libro "El Parto Natural y la Familia Cristiana". En este libro procuro mostrar que Dios tuvo la intención de que el parto fuera una experiencia segura y alegre para toda parturienta normal. Mi libro está escrito desde el punto de vista cristiano. Cada página que se escribió fue primero bañada en oraciones, buscando la guía de Dios. Hoy, este trabajo está preparado desde la misma perspectiva personal, no para convencer a nadie del cristianismo, sino simplemente para presentar mis respuestas como Cristiana a las objeciones que han surgido sobre el Parto Natural (Método de Read).

Hay dos objeciones principales a la filosofía del parto natural, como Read, y llevadas a la práctica por muchos otros. La primera objẹción está basada en los llamados principios científicos o naturales. Este afirma que la manera en la cual el cuerpo humano está constituído hace sentir dolor a la madre durante el paso de su hijo, consecuencia inevitable. Por consiguiente, fuera de toda bondad, esas gentes arguyen que ese dolor puede ser suprimido por drogas, anestesia, hipnosis, o distrayendo la atención de la madre, de alguna manera, del estímulo doloroso que pro- viene del área abdominal y pélvica durante el nacimiento.

La segunda objeción principal al parto natural es la religiosa que predica que el dolor en el parto fue impuesto por Dios a todas las mujeres como castigo por la desobediencia de la primera mujer Eva. Por lo tanto, es imposible evitar el dolor que Dios ha impuesto y que debe hacerse desaparecer con drogas, anestesia, hipnosis o distracción, fuera de la bondad de la mujer.

Mi argumento es que ninguna de esas objeciones al parto natural es válida. Sinembargo, estamos aquí confinados a una discusión de la segunda objeción, de que el dolor en el parto fué impuesto por Dios como justo castigo por el pecado. En mi prólogo yo declaro que:

"He aprendido, a través de años de paciente investigación, que esta interpretación es falsa. El concepto de una maldición de "dolor" a todas las mujeres no es cristiana. Esto no está en la Biblia. No se encuentra en la primitiva tradición Judía. No se encuentra en las enseñanzas de los cristianos primitivos".

\footnotetext{
* Presidenta de I.C.E.A.
} 
En el texto de mi libro (1) demuestro que un examen cuidadoso de todos los pasajes referentes al parto encontrados en la Biblia en lenguajes originales, revelan que solamente a la esterilidad se le llamó una "maldición". Las bendiciones de Dios se relacionaron con una mujer que iba a ser madre. No es posible ahora discutir todo lo referente a esto ni discutir las palabras Griegas - Hebreas, pero responderé brevemente mis conclusiones generales:

Mi tesis es que Dios es el Dios del amor y que su obra es buena. Las penas entraron al mundo por el pecado, desvirtuando el trabajo perfecto de Dios. Pero El amaba y cuidaba del hombre y sufría tanto por sus pecados como por sus sufrimientos. El probó su amor enviando a Cristo a este mundo. Cristo reveló su amor por los hombres no solamente enseñándonos quién era Dios, sino también curando a los enfermos, dando de comer a los hambrientos y consolando a los afligidos. Su crucifixión para librar a la humanidad del castigo del pecado fue la última expresión de su amor. El Cristo Resucitado continuó la dirección de la iglesia primitiva bajo el mismo ejemplo, enseñando a las gentes el amor de Dios y suministrándoles curaciones y bienestar físico lo más completo posible. Estas dos principales preocupaciones de la iglesia han continuado hasta el presente. El concepto de que una excepción a este ejemplo básico es el sufrimiento de una mujer en el parto es inaceptable. El comportamiento en el parto no está fuera de la línea ni del amor de Dios ni de la preocupación de la Iglesia.

Una de las grandes revelaciones de la Biblia es que Dios es el Dios del amor. Este es el tema principal repetido siempre en el viejo y nuevo
Testamento. El viejo Testamento dice:

"Su piedad, oh Señor, está en los cielos; y su fidelidad llega hasta las nubes. Qué excelente es su amorosa bondad, oh Dios. Por consiguiente, los hijos de los hombres ponen su confianza bajo la sombra de sus alas"!

El Nuevo Testamento dice:

"Para nosotros, la más grande demostración del amor de Dios hacia nosotros ha sido el envío de su único Hijo al mundo para darnos vida a través de él. Vimos amor real, no en el hecho de que amamos a Dios, sino de que él nos ama y envió su hijo para expiación personal de nuestras culpas. Si Dios nos amó tanto, seguramente nosotros, a nuestro turno, debemos amarnos los unos a los otros".

Pero aunque Dios es el Dios del amor, es también un Dios bendito, y no puede estar asociado con una maldad. Así, cuando la humanidad pecó, el resultado inmediato fue la muerte espiritual o sea la separación de la compañía de Dios, de la libre comunicación con El y de no recibir su permanente dirección. Y no culpemos solamente al primer hombre 0 a la primera mujer de esta separación de Dios por que cuál de nosotros no peca todos los días? Continuamente nos decimos chistosamente "Bueno, ninguno de nosotros es perfecto".

Pero Dios es perfecto. El efecto indirecto de las relaciones suspendidas del hombre con su Perfecto Hacedor ha sido pena, trabajo duro, sufrimientos, enfermedades, deficiencias mentales, odios entre unos y otros, guerras y toda clase de males de la humanidad. En estos resultados indi-

(1) Natural Childbird and the Christian Family. H. S. Wessel. Harper and Row Pub. New York 1963 
rectos se incluye el sufrimiento que puede causar el parto, conducido con ignorancia, enfermedad, pobreza, falta de aseo, miedo, o por dificultades inusitadas como una mala presentación del feto.

Cuando Dios dijo que el resultado traería pena y trabajo duro para el hombre y la mujer, El no estaba proclamando un castigo sino aseverando un hecho. Pena es el resultado inevitable de obrar mal. Para la mujer este dolor y trabajo se centraliza principalmente alrededor de la maternidad ya que esta tarea implica la mayor parte de los años de vida. Esto no se relaciona necesariamente con el parto, aunque tal vez en algunos casos. Eva, cuando nació cada uno de sus hijos, se alegró y alabó a Dios como cuando ella exclamó al nacimiento de Caín, "he recibido un hombre de Dios". Cuándo al corazón de Eva lo destrozó el dolor y la angustia? No fue cuando ella preparó el cuerpo muerto de su hijo menor para el entierro y comprendió en su corazón, que su primer hijo era un criminal? Caín, fuera de todo odio y toda envidia había matado a su piadoso hermano menor, Abel. Así la desobediencia de Eva a Dios, Ilenó de pena su propia cabeza, como Dios lo había predicado.

Pero el amor de Dios se lastimó con el pecado y sus consecuencias. Así, El mismo proporcionó el camino por el cual el hombre podía regresar a la confraternidad con El, entregándoles su Hijo, Jesucristo, encarnado en el género humano. Este es el mensaje principal de la Biblia.

“Dios amó tanto al mundo que dió a su único Hijo engendrado quien creyera en El no perecería sino tendría vida para siempre".

Cristo vino como un recordatorio viviente del amor de Dios por el hom- bre, porque El no solamente habló de Dios sino que iba haciendo el bien, curando enfermedades, socorriendo mentes agobiadas, dando de comer al hambriento, consolando al que sufría y resucitando a los muertos. Ninguno de los que vino a Cristo para que alimentara su cuerpo o su alma fue rechazado por EI. Y El nos dijo que aunque los pecados del hombre habian traído mucha pena, el cuidado amoroso de Dios todavía existía en el universo. Cristo nos recordó que "Dios hace que su luz aparezca sobre el mal y el bien y envía lluvia sobre los justos y los injustos".

Pero aunque Dios ama todavía a la humanidad, su santidad hizo imposible a los pecadores la comunión en sociedad con El. Por consiguiente Cristo, habiendo vivido una vida de perfecta obediencia hacia su padre, voluntariamente dio su vida para rescatarnos del pecado y así poder rehacer la amistad con Dios El Padre. El único obstáculo que permanece para impedir la comunión con Dios es la propia resistencia individual a hacerlo.

El sacrificio de Cristo mismo no solamente nos libra del paso de nuestras culpas ante Dios, sino que nos hace posible seguir la dirección de Dios para descubrir las verdades que libran del pecado y sus consecuencias. El amor de Dios por el mundo, a través de Cristo, despierta y estimula nuestro amor de unos a otros. Nos enteramos de nuestra responsab-i lidad de ayudar a libertar al mundo del peso del odio, ignorancia, sufrimiento, pobreza y enfermedades.

La historia de la iglesia primitiva en el Nuevo Testamento revela que los dos principales intereses eran la enseñanza de Dios en Cristo y atender las necesidades físicas de la gente. Durante los siglos de la era cris- 
tiana este énfasis ha sido continuo. El cristianismo ha estimulado el desarrollo de la ciencia médica, establecimiento de hospitales, instituciones educativas organizadas, agencias para cuidar de gentes sin hogar y agencias para distribuir artículos a los pobres. Ha estimulado también la medicina preventiva, enseñando a la gente las leyes de higiene, así como la curación de enfermedades por todos los medios conocidos en la profesión médica.

Pero hay unos pocos manchones en esta historia. Siempre en el cristianismo los individuos han seguido una doctrina, en lugar de vivir en constante compañía con el Cristo viviente, su amor por los otros se ha vuelto frío, y el amor de Dios no inspiró su propio amor. Uno de estos tristes ejemplos ha sido la fría actitud hacia el nacimiento, así que los cristianos y no cristianos compartieron la misma errónea actitud. Viendo el sufrimiento en los partos, que ocurre frecuentemente, algunos han afirmado que Dios envió ésto como castigo directo a la mujer. Ellos no pidieron consejo a Dios en este asunto ni estudiaron cuidadosamente la Biblia al respecto. Muy a menudo, aún hoy, quienes sostienen esta opinión rehusan discutir la cuestión. Ellos no oirán ni a Dios ni al hombre sino continuarán en su propia inquebrantable ignorancia.

Pero ellos están equivocados. El sufrimiento en el parto no es el resultado indirecto de la desobediencia del hombre a Dios como acabamos de explicar. Este es el resultado de los conocimientos inadecuados de higiene, pobre alimentación, escaso conocimiento de las funciones del cuerpo humano, e insuficientes cuidados médicos. $Y$ aún en nuestros países super-desarrollados, la ignorancia de la parturienta es aterradora con respecto a su desempeño inteligente en el parto.

Mientras en otros campos relacionados con el cuerpo humano se han visto sensibles métodos de prevención al dolor o enfermedad, el parto ha sido excluído. El tema ha sido salvar a la madre de los dolores de esta experiencia aunque esto implique un riesgo para la salud de la madre y el niño. Y en el esfuerzo de ayudar a la parturienta por medios artificiales no se reconoce que esto atribuye al hombre más amor e interés por ella que por Dios. En efecto, es lógico rescatarla de la crueldad de Dios, ignorantemente blasfemando de su amor.

Muchas mujeres intuitivamente han percibido que traer un hijo debe ser una buena experiencia y han mirado hacia ella con agradable anticipación. Pero muy a menudo se ignora $\tan$ edificante actitud o la mujer piensa que es extraordinaria. No se reconoce que esta intuición interior que muchas mujeres han experimentado, es una evidencia de su intimidad con el parto que Dios intentó para ella.

Cristo vino, murió y resucitó para libertarnos de la esclavitud del pecado y del sufrimiento. El nos dio la gracia para llevar el sufrimiento que todavía no sabemos como aliviar o prevenir. Pero en tal sufrimiento, El nos dá discernimiento sobre el camino por el cual esta misma dificultad se puede obviar para que no ocurra a los otros. No solamente el amor a El nos induce a encontrar respuestas sino que mirándolo a El y restableciendo nuestras relaciones con El se encuentran las respuestas completas a todas nuestras necesidades humanas. Cuánto más rápido no progresa- 
rían las investigaciones médicas en todos los campos de interés si nosotros humilde y fervorosamente, a diario, pedimos a Dios que nos descubra el secreto del Universo que permanece oculto porque nosotros negligentemente no se lo preguntamos?

Amigos, ustedes que están trabajando duramente para hacer del parto una experiencia feliz y segura para las mujeres y sus hijos, están empeñados en el trabajo de Dios. El que ustedes puedan realizarlo $\circ$ no es Dios quien ha puesto ternura e interés en sus corazones para ellos. Es El quien designa la unidad de la familia, padre-madre-hijo. $Y$ así El es quien le ha dado el deseo de fomentar la intimidad entre padre, madre e hijo, para que el amor dentro de la unidad de la familia tenga más fuerza contra la influencia destructiva del pecado, todavía desenfrenado en nuestro mundo de hoy.

El parto puede ser una experiencia bendita, una alegría, cuando la ignorancia y el miedo de las mujeres se reemplaza por fé y entrenamiento. Dios muestra esto como una buena experiencia. Y si no lo es nunca podremos atribuir la culpa a El. Nunca nos avergoncemos de trabajar con $\mathrm{El}$ por esta causa.

$Y$ también recordemos utilizar solamente sus métodos al tratar con quienes se oponen fuertemente a lo que estamos haciendo. Pero si nosotros respondemos con resentimiento y enojo destruimos los mismos ideales que estamos procurando fomentar. Cristo nos dijo y nos lo demostró con el ejemplo de su vida, que por medio del amor, el perdón y la paz se corrige lo erróneo. El dijo:

"Ama a tus enemigos, bendice a los que te maldicen, haced el bien a los que te odian, y rezad por aquellos que maliciosamente te han aprovechado y te persiguen"

Mientras no podamos reprimirnos de hablar en todas partes de las verdades que hemos aprendido sobre el parto, recordemos que siempre debemos "hablar de la verdad en el amor". 